\title{
Leben, Wesen und Wirken Liebigs
}

Justus Liebig wurde am 12. Mai 1803 in Darmstadt als zweites von zehn Kindern geboren. Schon früh war er im Geschäft seines Vaters, eines Materialwarenhändlers, mit der Bereitung von Farben und Firnissen vertraut; seine Freizeit benutzte er, um alle wissenschaftlichen Bücher zu verschlingen, deren er habhaft werden konnte. So kam es, daß er in dem berühmten Ludwig-GeorgsGymnasium kein Musterschüler war, und daß er es schon als Sekundaner verließ. Eine Stelle als Apothekerlehrling in Heppenheim (Bergstraße) gab er bald auf, da er dort keine wissenschaftliche Fönderung bekam. Nach einem kurzen Aufenthalt im Elternhaus - die Mutter, angenommenes Kind des Ackerbürgers Moser, die ihm das Äußere, die Hakennase, die leuchtenden Augen und offenbar ihre besonderen Gaben, Schnelligkeit im Denken und Handeln und Organisationstalent, vererbt hatte, war dort der geistige Mittelpunkt - be.gann er 1820 das Studium der Chemie an der Universität Bonn bei dem damals angesehenen Professor Kastner. Ihm folgte er 1821 nach Erlangen, wo er sich mit dem Dichter August Graf von Platen innig befreundete. Die Verfolgung »demokratischer " Studenten durch die Polizeiorgane trieb ihn nach Hause zurück. Der weitschauende Großherzog Ludwig I. von Hessen ermöglichte ihm nun das in Liebigs Vorstellung Höchste: einen Studienaufenthalt in Paris, dem damaligen Zentrum der Naturwissenschaften. Dort hörte er Vorlesungen bei Thénard, Dulong, Petit, Laplace und Cuvier, und zwar solche mit begleitenden Experimenten; bei Vauquelin und vor allem Gay-Lussac lernte er exaktes Experimentieren. Mit diesem veröffentlichte er eine bedeutsame Arbeit über das Knallsilber, das ihn schon früh beschäftigt hatte und dessen »Isomerie « mit cyansaurem Silber er später mit F. Wöhler auffinden sollte. Sie machte ihn in Forscherkreisen so bekannt, daß der hessische Großherzog, von Alexander von Humboldt gut beraten, den 21jährigen zum außerordentlichen Professor an der Landesuniversität Gießen ernannte (1824), nachdem er 1823 in Erlangen »in absentia « zum Doktor promoviert worden war. Schon 1825 wunde er ordentlicher Professor für Chemie. 28 Jahre, seine fruchtbarsten, hat er in Gießen zugebracht; an ihrem Ende hatte die Chemie, wesentlich durch ihn, ein neues Gesicht.

Nicht nur sein wissenschaftliches Genie, seine Härte gegen sich und seine unglaubliche Arbeitskraft haben das bewirkt, sondern nicht weniger seine einzigartige Fähigkeit, bedeutend ältere und junge Forscher an sich zu ziehen, sie $\mathrm{zu}$ Freunden zu machen und sie in engem Kontakt mit ihm zu Leistungen an- 
zuspornen. Er schuf so ein geistiges Kraftfeld, das das kleine Gießen weltbekannt machte. Schüler aus seiner Gießener Zeit waren so hervorragende Forscher wie A. W. v. Hofmann, Frankland, Wurtz, Kekulé, Gerhardt, R. Fresenius, Williamson, Pettenkofer und Jacob Volhard. Wien, Petersburg und Heidelberg bemühten sich vergeblich, ihn zu gewinnen; trotz beengender Laboratoriumsverhältnisse in Gießen hielt er dem Großherzog, der ihn 1845 in den Freiherrnstand erhob, die Treue. Erst 1852 nahm er einen Ruf nach München an, wo er, nun eine Weltberühmtheit, noch zwei Jahrzehnte wirkte, um vor allem der Agrikulturchemie Geltung zu verschaffen. Sie wurde sein Lieblingskind, brachte ihm freilich auch schwerste Enttäuschungen, Mißerfolge und persönliche Spannungen. Allein auf diesem Gebiet hat er für die Menschheit mehr geleistet als wohl je ein König oder Feldherr. Am 18. April 1873 ist er, fast 70 Jahre alt, in München gestorben.

Trotz seiner großen, für die ganze Menschheir bestimmenden Leistungen wäre Liebig nicht so markant im Gedächtnis seiner Zeitgenossen und Nachfahren geblieben ohne die Faszination, die von seiner Persönlichkeit ausging. Wollte man sein vielschichtiges Wesen durch einen einzigen Zug kennzeichnen, so müßte er "Leidenschaftlichkeit« heißen. Der junge Feuerkopf, der auch die bedeutenden Geister seiner Zeit, mit denen er in Berührung kam, in seinen Bann zog, der mit 21 Jahren Meister war und von da ab Wissen nur noch ausströmte, scheint eine fast magische Anziehungskraft auf jung und alt ausgeübt zu haben. Mit den Jahren aber kam eine zunehmende Reizbarkeit hinzu, die sich nicht selten in heftigen, ja verletzenden Briefen, Kritiken und Rezensionen entlud, die ihm viel Leid eintrug und feste Freundschaften wie die mit $\mathbf{v}$. Platen und die jahrzehntelange mit dem großen Berzelius zerbrach. Unter diesen Reaktionen seines Wesens litt er selbst schwer, das beweisen seine temperamentvollen Briefe, deren er wohl mehrere tausend geschrieben hat. Sie zeigen trotz gelegentlicher Voreiligkeit im Urteil über Menschen, trotz Heftigkeit, Schroffheit und Sarkasmus auch viel Warmherzigkeit und unbegrenzte Hilfsbereitschaft. Freundschaft war ihm unentbehrlich, doch währte lebenslänglich nur die zu Friedrich Wöhler (1800-1882), seinem "guten Geist « bei vielen Angelegenheiten und Entschlüssen. Er war nicht gefeit gegen Irrtümer, war oft in Kontroversen, auch mit bedeutenden Zeitgenossen, verwickelt; erkannte er aber eigene Fehler, so war er mit seiner strengen Wahrheitsliebe sofort zur Berichtigung und Entschuldigung bereit. Als Wissenschaftler war er früh auf höchster Stufe, als Mensch, als Charakter, wuchs er bis zum Tode. Die Photographien aus seinen letzten Lebensjahren zeigen das besonders deutlich, wenn man sie mit den Bildern aus frühen und mittleren Jahren vergleicht. Wir sehen einen herrlich durchgeistigten Kopf, der alle edlen Anlagen des XIX. Jahrhunderts repräsentieren könnte.

Liebigs wissenschaftliche Leistungen auf den Gebieten der Organischen und Anorganischen Chemie, der Physiologie und Agrikulturchemie sind zu um- 
fangreich und zu vielseitig, als daß sie auch nur in Stichworten voll gewürdigt werden könnten; deshalb sollen ihrer nur einige erwähnt werden.

Die Analytische Chemie verdankt ihm die nähere Ausgestaltung einer im Prinzip noch heute angewandten Methode, um Kohlenstoff und Wasserstoff in organischen Verbindungen zu bestimmen. Zahlreiche Laboratoriumsgeräte hat er entwickelt (z. B. den »Fünfkugelapparat «) oder in der Praxis eingeführt (den Liebigkühler); viele wichtige Naturstoffe hat er erstmals isoliert und auf synthetischem Wege Stoff von großer Bedeutung darzustellen gelehrt (Chloroform, Chloralhydrat usw.). Er war Mitschöpfer der sog. Radikal-Theorie, einer Etappe zu unseren heutigen theoretischen Erkenntnissen (vgl. seine Untersuchung mit Friedr. Wöhler aus dem Jahre 1832 "Über das Radikal der Benzoesäure «).

Besonders folgenschwer waren seine Gedanken und Entdeckungen auf dem Gebiet der Agrikulturchemie. Man darf ihn, ohne die Leistungen von Albrecht Thaer und von Ludwig Sprengel zu schmälern, als deren Schöpfer ansehen. Er erkannte klar: Was man den Äckern mit den Ernten an Nährstoffen ent́nimmt, das muß man ihnen wieder zuführen. Ohne diese seine damals revolutionäre Leistung, die Hunger, Not und Elend durch wesentliche Steigerung der Ernteerträge bannen half, wäre die dann so schnelle Vermehrung der Menschheit nicht möglich gewesen. Nach seiner Mineraltheorie, die er der "Humustheorie« von Thaer entgegensetzte, sind die hauptsächlichen Nährstoffe der grünen Pflanze außer Kohlenstoff, Wasserstoff, Sauerstoff und Stickstoff die sechs »mineralischen Nährstoffe«: Schwefel, Phosphor, Eisen, Calcium, Magnesium und Kalium. Das von ihm außerdem als nötig angegebene Silicium bezeichnen wir heute als Spurenelement. Sein »Gesetz vom Minimum « besagt: Der Pflanzenertrag richtet sich nach dem Nährstoff bzw. dem Element, das in geringster Menge für die Pflanze verfügbar ist. Diese mit großer Eindringlichkeit vorgetragenen Lehren hatten u. a. die Entwicklung der Superphosphat-Industrie, vor allem aber die zur Erzeugung des Stickstoffs aus der Luft zur Folge; sie gaben den vorher vernachlässigten Kalisalzen der Staßfurter Salzlager Bedeutung für die Landwirtschaft in aller Welt, kurz, sie bewiesen besonders eindringlich, welche ungeheure materielle Auswirkung ein am Schreibtisch ersonnener wissenschaftlicher Gedanke haben kann.

Von hier aus hat Liebig sich dann folgerichtig der Physiologie zugewandt. Er erkannte, in den Grundzügen richtig, das, was wir heute "Photosynthese" nennen. Seine volkstümlichste, aber gewiß nicht größte Leistung war die Darstellung des Fleischextraktes, der seinen Namen weithin bekannt machte. Viel tiefere Wirkung hatten seine beiden Werke: "Die organische Chemie in ihrer Anwendung auf Agrikultur und Physiologie« (1840) (das dem Problem der Pflanzenernährung galt) und »Die organische Chemie in ihrer Anwendung auf Physiologie und Pathologie« (1842), die sog. »Tierchemie«.

Durch die Henausgabe von Handbüchern der Chemie, vor allem aber durch die 
der »Annalen der Chemie und Pharmazie«, die als »Justus Liebigs Annalen der Chemie « noch heute seinen Namen tragen, hat er Wesentliches für das kritische chemische Schrifttum geleistet. Seine »Chemischen Briefe (1844) öffneten dem Laien einen Blick in die riesenhaften Gefilde der Chemie und machten sie populär.

Die nachhaltigste Wirkung aber auf die weitere Entwicklung der Chemie hat Liebig als akademischer Lehrer ausgeübt. Er hat die Methode des chemischen Unterrichts eingeführt, die in den Grundzügen noch heute angewandt wird, in der Reihenfolge: qualitative, dann quantitative Analyse, präparatives Arbeiten, selbständiges Forschen. Er erzog seine Schüler zum wissenschaftlichen Denken und machte das Forschen lehrbar. Mit der bezwingenden Eindringlichkeit seines Wesens hat er sich fast 3 Jahrzehnte dieser Aufgabe gewidmet. Seine Schüler dankten es ihm, indem sie überall in der Kulturwelt seine Art des Unterrichts einführten und die Chemie zu ungeahnter Blüte brachten. Liebig hat die Chemie zu einer selbständigen Wissenschaft gemacht.

Ansicht vom Analytischen Laboratorium

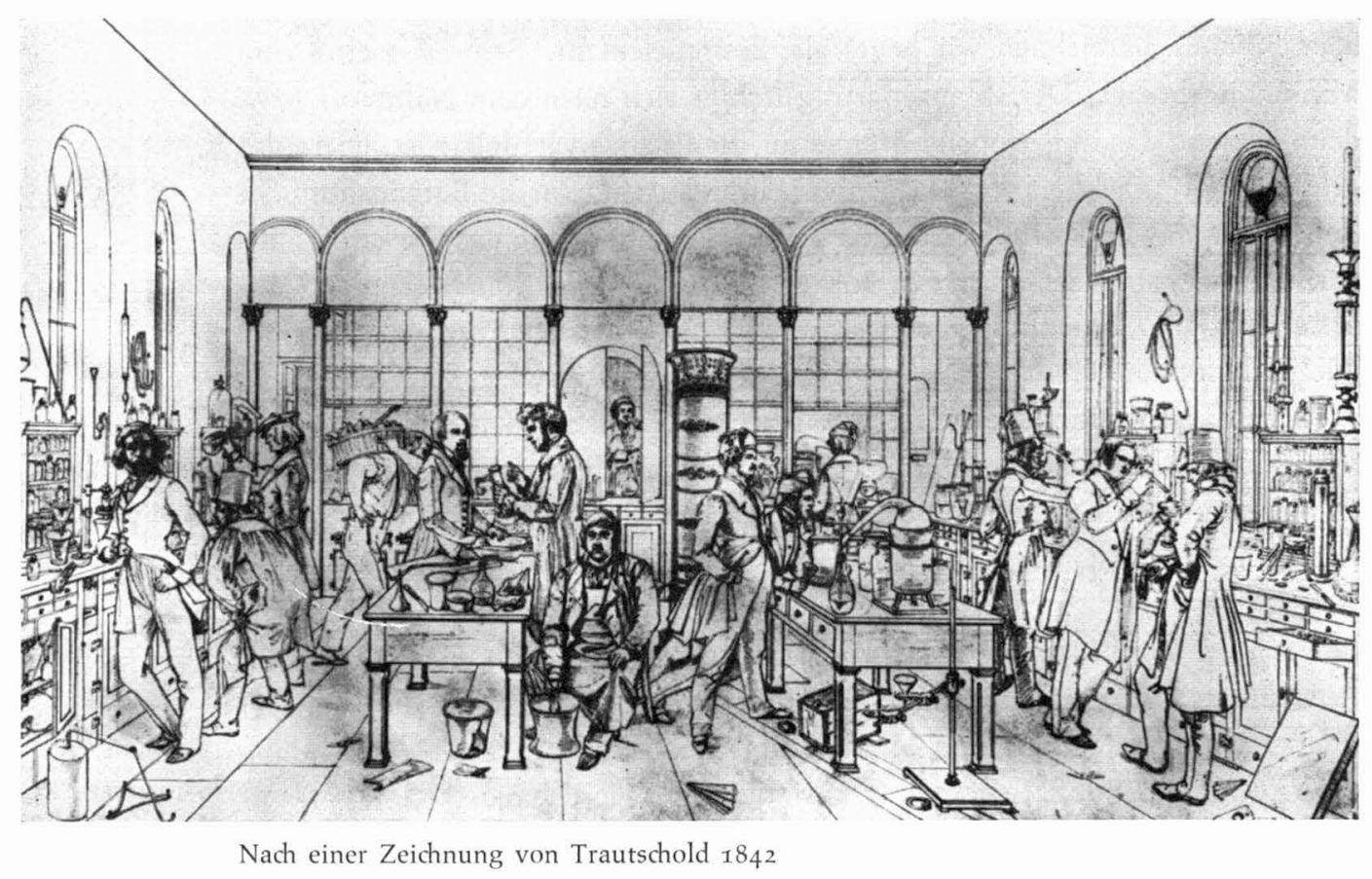

